\title{
Up-regulation of UVRAG by HDAC1 Inhibition Attenuates 5FU-induced Cell Death in HCT116 Colorectal Cancer Cells
}

\author{
YOON KYUNG JO ${ }^{1 *}$, NA YEON PARK ${ }^{1 *}$, JI HYUN SHIN ${ }^{1}$, DOO SIN JO ${ }^{1}$, JI-EUN BAE ${ }^{1}$, \\ EUN SUN CHOI ${ }^{1}$, SUNGHO MAENG ${ }^{1}$, HONG BAE JEON ${ }^{2}$, SEON AE ROH ${ }^{3}$, \\ JONG WOOK CHANG ${ }^{4}$, JIN CHEON KIM ${ }^{3,5}$ and DONG-HYUNG CHO ${ }^{1}$ \\ ${ }^{1}$ Department of Gerontology, Graduate School of East-West Medical Science, \\ Kyung Hee University, Seoul, Republic of Korea; \\ ${ }^{2}$ Biomedical Research Institute, MEDIPOST Corporation, Seongnam, Republic of Korea; \\ ${ }^{3}$ Asan Institute for Life Sciences, Asan Medical Center, Seoul, Republic of Korea; \\ ${ }^{4}$ Stem Cell \& Regenerative Medicine Institute, Samsung Medical Center, Seoul, Republic of Korea; \\ ${ }^{5}$ Department of Surgery, University of Ulsan College of Medicine, Asan Medical Center, Seoul, Republic of Korea
}

\begin{abstract}
The ultraviolent irradiation resistance-associated gene (UVRAG), a component of the Beclin 1/autophagyrelated 6 complex, regulates the autophagy initiation step and functions in the DNA-damage response. UVRAG is frequently mutated in various cancer types, and mutations of UVRAG increase sensitivity to chemotherapy by impairing DNA-damage repair. In this study, we addressed the epigenetic regulation of UVRAG in colorectal cancer cells. UVRAG expression was increased in cells treated with histone deacetylase (HDAC) inhibitors, such as valproic acid and suberoylanilide hydroxamic acid. Down-regulation of HDACl enhanced UVRAG expression in colorectal cancer cells. In addition, both chemical and genetic inhibition of HDAC1 reduced the activation of caspase-3 and cytotoxicity in 5-fluorouracil (5FU)-treated cancer cells. In contrast, UVRAG overexpression inhibited caspase activation and cell death in 5FU-treated cells. Taken together, our findings suggest that up-regulation of UVRAG by HDACl inhibition potentiates DNA-damage-mediated cell death in colorectal cancer cells.
\end{abstract}

*These Authors contributed equally to this study.

Correspondence to: Jin Cheon Kim, MD, Ph.D., Department of Surgery, University of Ulsan College of Medicine, Asan Medical Center 88, Olympic-ro 43-gil, Songpa-gu, Seoul 05505, Republic of Korea. Tel: +82 222587295, e-mail: jckim@amc.seoul.kr; DongHyung Cho, Ph.D., Graduate School of East-West Medical Science, Kyung Hee University, 1732, Deogyeong-daero, Giheung-gu, Yongin-si, Gyeonggi-do 17014, Republic of Korea. Tel: +82 312012749, e-mail: dhcho@khu.ac.kr

Key Words: UVRAG, HDAC1, epigenetics, 5FU, colorectal cancer.
Autophagy has important roles in cellular homeostasis through the degradation of useless or damaged proteins and organelles via lysosomes $(1,2)$. The primordial function of autophagy is a response to stress, such as starvation, oxidative stress, and ion stress $(1,2)$. Given that multiple signaling pathways are involved in the regulation of autophagy progress, various autophagy-related (ATG) proteins and other autophagy-regulatory proteins have been identified (2). The early years of autophagy research focused on the dynamic membrane rearrangements and posttranslational modifications of ATG proteins, whereas recent progresses has elucidated its regulation by gene expression (3-6). Several transcription factors, such as farnesoid $\mathrm{X}$ receptor (FXR), cAMP response element-binding protein, and transcription factor EB (TFEB) coordinately control major autophagy regulators $(3,4)$. In addition, autophagyrelated and lysosomal genes are up-regulated through direct binding of TFEB to co-activator-associated arginine methyltransferase 1 (CARM1) under starvation conditions (5). Recently our group also reported that methyltransferase G9 inhibition leads to increased expression of autophagyrelated genes and directly regulates BECLIN 1 (BECN1)/ATG6 expression (6).

Among various autophagy regulatory proteins, the ultraviolent irradiation resistance-associated gene (UVRAG) is a putative mammalian ortholog of the yeast Vps38 component recruiting BECN1/PI3K complex protein. UVRAG promotes autophagy via activating the BECN1/PI3K complex, but suppresses apoptosis and tumorigenicity of cancer cells by inhibiting cell proliferation and activation of BCL2 associated $\mathrm{X}$, apoptosis regulator $(7,8)$. UVRAG frameshift leads to its expression as a truncated form in colorectal cancer (9). Moreover, UVRAG prevents cells from accumulating 
A

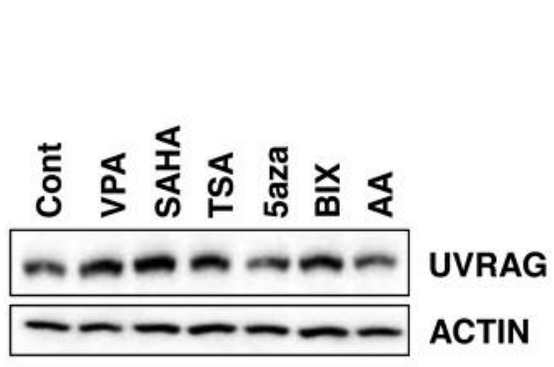

B

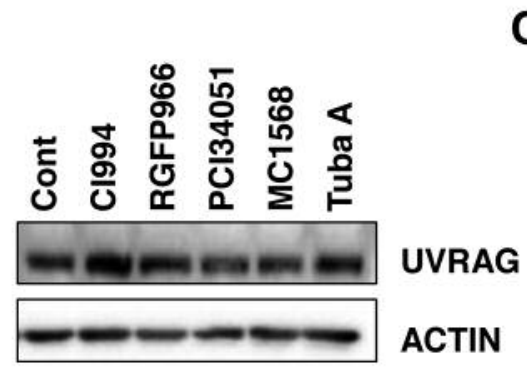

C

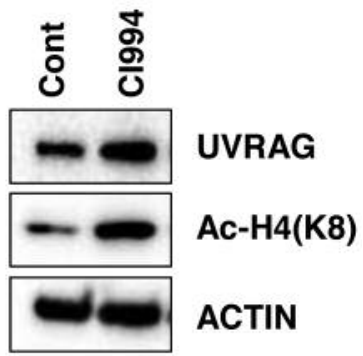

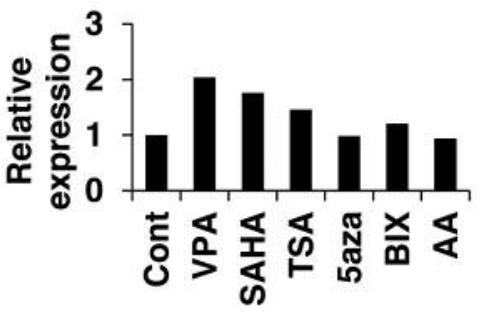

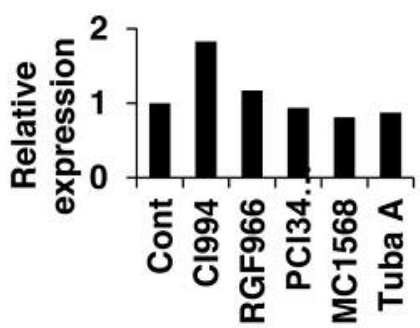

Figure 1. Ultraviolent irradiation resistance-associated gene (UVRAG) expression is induced by histone deacetylase (HDAC) inhibitor in HCT116 cells. A: HCT116 cells were treated with dimethylsulfoxide (Cont) or epigenetic regulators valproic acid (VPA;1 mM for 72 h), suberoylanilide hydroxamic acid (SAHA; $5 \mu \mathrm{M}$ for $24 \mathrm{~h}$ ), trichostatin A (TSA; $300 \mathrm{nM}$ for $24 \mathrm{~h}$ ), 5-aza-2'-deoxycytidine (5aza; $5 \mu \mathrm{M}$ for 24 h), BIX-01294 (BIX; $10 \mu M 24 \mathrm{~h})$ or anacardic acid $(A A ; 5 \mu M$ for $24 \mathrm{~h})$. The cells were harvested and analyzed by western blotting with anti-UVRAG. B: HCT116 cells

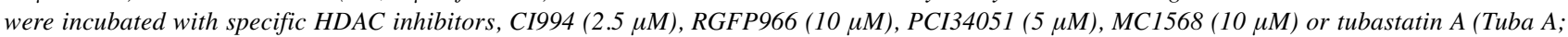
$10 \mu M)$ for 24 h. UVRAG expression was assessed by western blotting and normalized with actin expression. C: HCT116 cells were treated with CI994 (2.5 MM) for $24 \mathrm{~h}$ treated and expression of UVRAG and acetyl histone (Ac-H4, K8) were analyzed by western blotting.

abnormal chromosomes, thereby, developing oncogenic mutation (10). Because autophagy maintains cellular homeostasis under various stress conditions, dysregulation of autophagy is involved in many diseases such as cancer, diabetes and neurodegeneration (11). However, the precise regulatory mechanism of autophagy is not fully understood. In this study, we addressed epigenetic regulation for autophagy regulators and found that UVRAG is modulated by histone deacetylase (HDAC) in colorectal cancer cells.

\section{Materials and Methods}

Reagents. Valproic acid (VPA), trichostatin A, BIX-01294, 5-aza2'-deoxycytidine, anacardic acid, and 3-(4, 5-dimethylthiazol-2-yl)2, 5 diphenyltetrazolium bromide (MTT) were purchased from Sigma Aldrich (St. Louis, MO, USA). Suberoylanilide hydroxamic acid (SAHA) was provided by Crystal Genomics Co. (Seoul, S. Korea). Inhibitors CI994, RGFP966, PCI34051, MC1568 and tubastatin A were purchased from Selleckchem (Houston, TX, USA). 5-Fluorouracil (5FU) was purchased from JW Pharma (Seoul, S. Korea).

Cell culture and transfection. HCT116 colorectal cancer cells were obtained from the American Type Culture Collection (ATCC, Manassas VA, USA). The cells were cultured at $37^{\circ} \mathrm{C}$ in a $5 \% \mathrm{CO}_{2}$ incubator and maintained in RPMI-1640 containing $10 \%$ fetal bovid serum and $1 \%$ penicillin/streptomycin (Invitrogen, Carlsbad, CA,
USA). Validated siRNAs targeting HDAC1 (\#1, 5'-CACCCGGA GGAAAGTCTGTTA-3'; \#2, 5'-GACGAGTCCTATGAGGCCATT3') or scrambled control siRNA (Sc; 5'-CCUACGCCACCAA UUUCGU-3') were synthesized from Genolution (Seoul, S. Korea). Both plasmids and siRNAs were transfected using Lipofectamine 2000 (Invitrogen) according to the manufacturer's protocol.

MTT cell viability assay. HCT116 cells $(\sim 10,000)$ cultured in 96well plates were either treated with CI994 $(2.5 \mu \mathrm{M}$ for $24 \mathrm{~h})$ or transfected with HDAC1 siRNA for $48 \mathrm{~h}$. Then the cells were treated with or without $20 \mathrm{mg} / \mathrm{ml} 5$-fluorouracil for additional $24 \mathrm{~h}$. For MTT assay, $10 \mu \mathrm{l}$ MTT solution $(5 \mathrm{mg} / \mathrm{ml})$ was added to the cells which were then incubated at $37^{\circ} \mathrm{C}$ for $4 \mathrm{~h}$. The reaction was stopped with solubilizing solution $(10 \% \mathrm{SDA}$ and $0.01 \mathrm{M} \mathrm{HCl})$ to each well. The absorbance change was measured at $570 \mathrm{~nm}$ by a microplate reader (VICTOR X3; PerkinElmer, Waltham, MA, USA). The cell viability was calculated as follows: chemical treated cells/untreated cells $\times 100$.

Western blotting. HCT116 cells treated with VPA (1 mM for $72 \mathrm{~h})$, SAHA ( $5 \mu \mathrm{M}$ for $24 \mathrm{~h}$ ), trichostatin A (300 nM for $24 \mathrm{~h}), 5$-aza-2'deoxycytidine (5 $\mu \mathrm{M}$ for $24 \mathrm{~h})$, BIX-01294 (10 $\mu \mathrm{M} 24 \mathrm{~h})$, anacardic acid $(5 \mu \mathrm{M}$ for $24 \mathrm{~h})$, CI994 $(2.5 \mu \mathrm{M}$ for $24 \mathrm{~h})$, RGFP966 $(10 \mu \mathrm{M}$ for $24 \mathrm{~h}), \mathrm{PCI} 34051$ ( $5 \mu \mathrm{M}$ for $24 \mathrm{~h}), \mathrm{MC} 1568(10 \mu \mathrm{M}$ for $24 \mathrm{~h})$ or tubastatin $\mathrm{A}(10 \mu \mathrm{M}$ for $24 \mathrm{~h})$ were harvested using cell lysis buffer. All cell lysates were prepared with $2 \times$ Laemmli sample buffer [62.5 $\mathrm{mM}$ Tris- $\mathrm{HCl}$ ( $\mathrm{pH} 6.8$ ), $2 \%$ sodium dodecyl sulfate (SDS), $25 \%$ glycerol, 5\% $\beta$-mercaptoethanol, $0.01 \%$ bromophenol blue] (BioRad, Hercules, CA, USA). Proteins (approximately $50 \mu \mathrm{g}$ ) were 

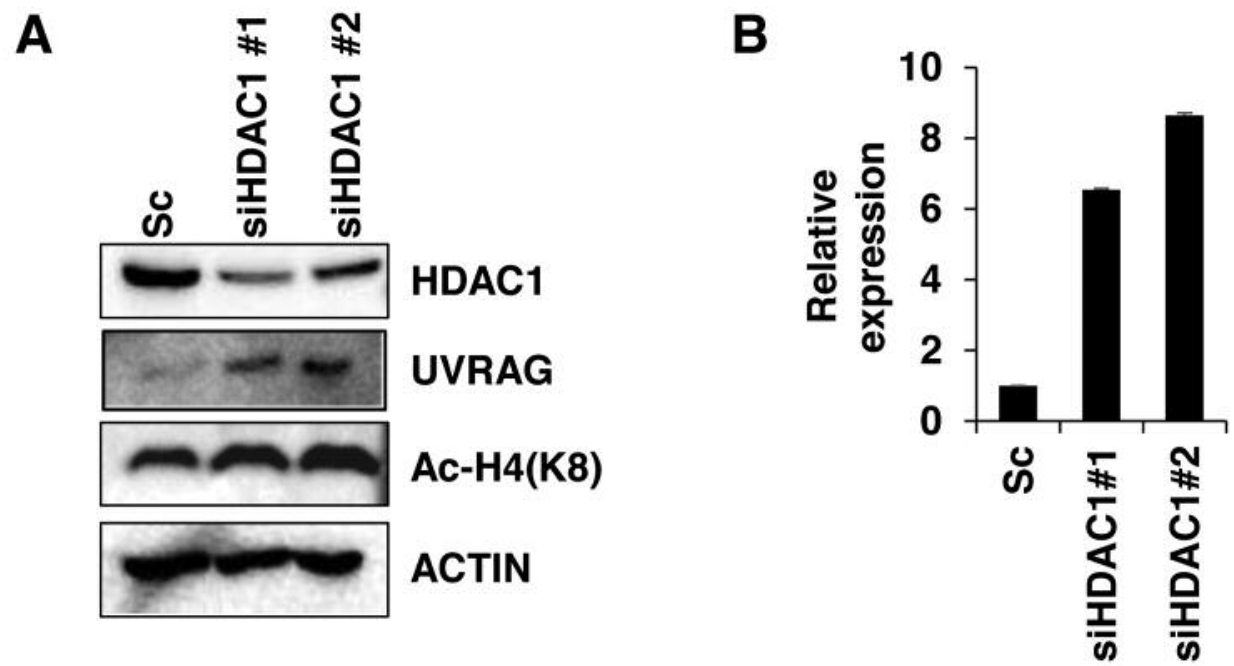

Figure 2. Histone deacetylase 1 (HDAC1) suppression induces ultraviolent irradiation resistance-associated gene (UVRAG) expression in HCT116 cells. A: HCT116 cells were transiently transfected with either siRNA against HDAC1 (siHDAC1 \#1 and \#2) or scrambled siRNA (Sc) as a negative control. After 3 days, the cells were analyzed by western blotting and the level of HDAC1 and UVRAG protein was detected with specific antibodies. $B:$ The protein expression was quantified by densitometric image analysis of the western blots.

quantified by using Bradford solution (BioRad). Then the samples were resolved by SDS-polyacrylamide gel electrophoresis, and transferred to polyvinylidene difluoride membrane. After blocking, the membranes were incubated with specific primary antibodies; anti-UVRAG (ab174550, Abcam, Cambridge, UK), anti-acetyl histone (sc-8660; Santa Cruz Biotechnology, Santa Cruz, CA, USA), anti-HDAC1 (sc7872; Santa Cruz Biotechnology), anti-poly (ADP-ribose) polymerase (\#9542; Cell Signaling, Beverly, MA, USA), anti-cleaved caspase 3 (\#9661; Cell Signaling), anti-green fluorescent protein (GFP) (sc8334; Santa Cruz Biotechnology) and anti-actin (\#MAB1501; Milipore, Temecula, CA, USA). For protein detection, the membranes were incubated with horseradish peroxidase-conjugated secondary antibodies and signals were detected with EzWestLumi Plus (ATTO, Tokyo, Japan).

Statistical analysis. Data were obtained from least three independent experiments, and presented as means \pm S.E.M. Statistical evaluation of the results was performed with one-way ANOVA. Data represent \pm standard error of the mean (S.E.M.) from more than three independent experiments, $\mathrm{n}=3$.

\section{Results}

UVRAG expression is increased by HDAC inhibitors in colorectal cancer cells. To identify novel epigenetic target proteins, we addressed expression change of various autophagy regulatory proteins in the context of epigenetic changes in colorectal cancer cells. HCT116 cells were treated with different chromatin remodeling inhibitors, including HDAC inhibitors. Then we analyzed the level of ATG proteins such as ATG4, ATG6, ATG7, ATG10, WD repeat protein interacting with phosphoinositide 2 (WIPI2), and UVRAG. Among the investigated proteins, we found that UVRAG expression was highly increased in HCT116 cellstreated with VPA and SAHA (Figure 1A). However, other proteins were not notably altered under those conditions (data not shown), suggesting that expression of UVRAG is influenced by HDAC inhibitors. HDAC proteins are grouped into four classes (class I, IIa, IIb, III, and IV) based on their sequence similarity and function (12).

As $U V R A G$ was up-regulated by HDAC inhibitors VPA and SAHA, we further addressed which HDAC proteins regulate UVRAG expression. HCT116 cells were treated with subtypeselective inhibitors: class I inhibitors: CI994, RGF966 and PCI34051; class IIa inhibitor MC1568; and class IIb inhibitor tubastatin A. Interestingly, among the tested HDAC inhibitors, UVRAG expression was substantially increased in cells treated with CI994 (Figure 1B). HDAC1, HDAC2, HDAC3, and HDAC8 are class I HDAC proteins, but CI994 has higher selective inhibition of HDAC1 and HDAC3 than other HDAC proteins. However, UVRAG expression was not changed by another class I inhibitor, RGFP966, which has highly selective inhibition for HDAC3 (Figure 1B). These results imply that HDAC1 is involved in UVRAG expression in HCT116 cells (Figure 1B). We also confirmed increased histone acetylation in cells treated with HDAC inhibitor CI994 (Figure 1C).

To further examine whether UVRAG expression is controlled by HDAC1, HDAC expression was suppressed by specific siRNA and UVRAG expression was investigated. Consistent with the chemical inhibitor experiment, reduction 
A

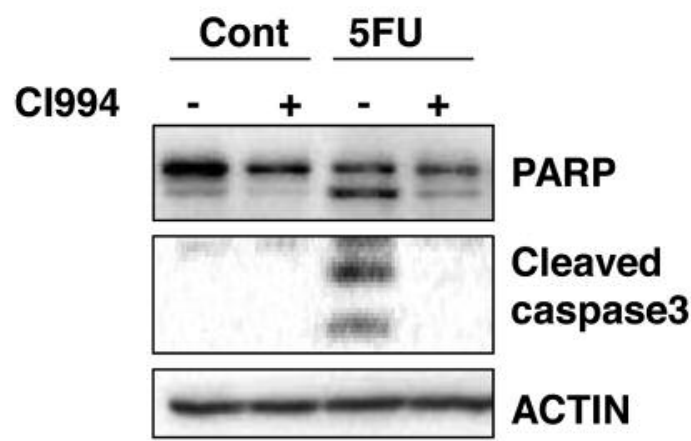

C

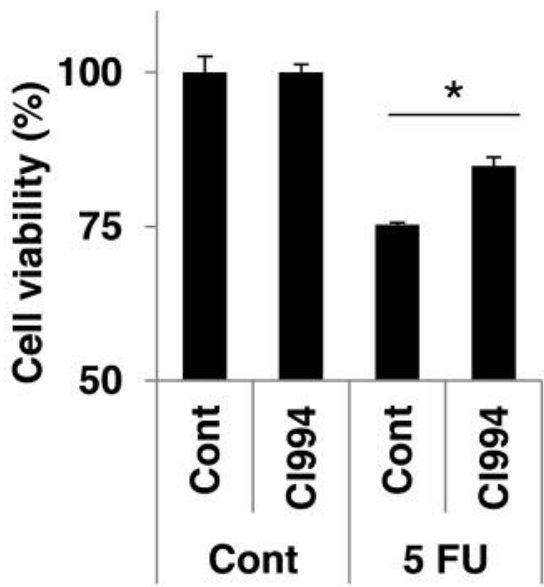

B SiHDAC1
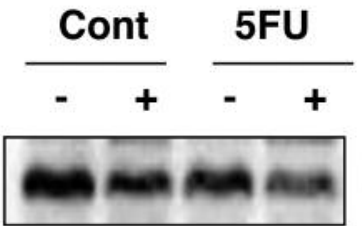

HDAC1

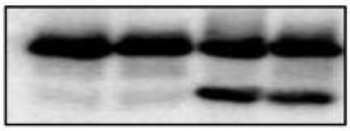

PARP

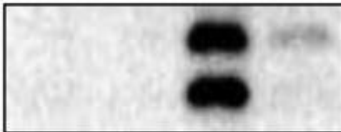

Cleaved

caspase 3

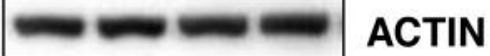

D

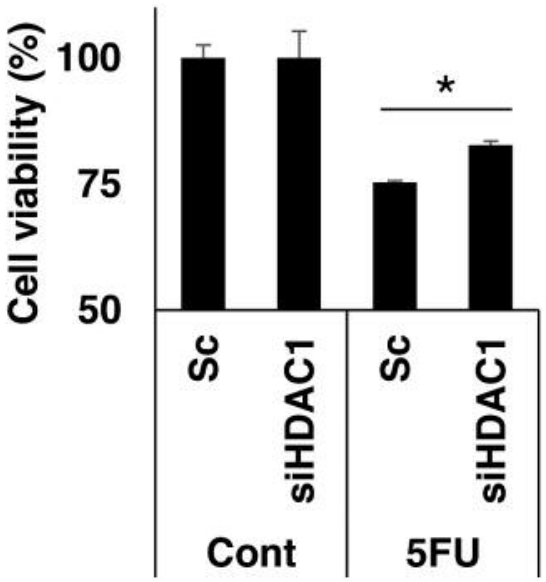

Figure 3. Inhibition of histone deacetylase 1 (HDAC1) attenuates cell death in 5-fluorouracil (5FU)-treated cells. A: HCT116 cells pre-treated with HDAC inhibitor CI994 were additionally incubated in the presence or absence of $5 F U(20 \mathrm{mg} / \mathrm{ml})$ for $24 \mathrm{~h}$. The cells were subjected to western blotting with antibodies to poly (ADP-ribose) polymerase (PARP) and cleaved caspase-3. B: HCT116 cells were transfected with HDAC1 siRNA. After $48 \mathrm{~h}$ transfection, the cells were further incubated with $5 F U(20 \mathrm{mg} / \mathrm{ml})$ for $24 \mathrm{~h}$. The cells were analyzed with western blotting with antibodies to HDAC1, PARP and cleaved caspase-3. C: HCT116 cells pre-treated with CI994 were additionally incubated in the presence or absence of 5FU $(20 \mathrm{mg} / \mathrm{ml})$ for $24 \mathrm{~h}$. Then, cell viability was measured by the MTT assay. D: HCT116 cells were transfected with HDAC1 siRNA. After $48 \mathrm{~h}$ transfection, the cells were incubated with $5 F U(20 \mathrm{mg} / \mathrm{ml})$ for $24 \mathrm{~h}$. Then cell viability was measured by the MTT assay. Data are presented as the mean \pm SEM from three independent experiments $(n>3)$. *Significantly different at $p<0.05)$.

of HDAC1 by RNAi resulted in increased UVRAG expression as well as histone acetylation in HCT116 cells (Figure 2). Taken together, these results indicated that HDAC1 negatively controls UVRAG expression in colorectal cancer cells.

Inhibition of HDAC1 attenuates 5FU-induced cell death in HCT116 cells. Since UVRAG is a multifunctional protein that suppresses cell death, we further investigated a role of induced UVRAG expression by inhibiting HDAC1 in 5FU-treated cells. 5FU, a pyrimidine analog, functions via the irreversible inhibition of thymidylate synthase and has been used in the treatment of various types of cancers, including colorectal, breast, gastrointestinal and cervical cancer. In accordance with this notion, we observed an increase of caspase- 3 activation and cleavage of PARP1 in 5FU-treatd HCT116 cells (Figure 3A). However, both the treatment with CI994 and knockdown of $H D A C 1$ significantly suppressed the increased activation of caspase- 3 in 5FU-treated cells (Figure $3 \mathrm{~A}$ and $\mathrm{B}$ ). In addition, cell death induced by $5 \mathrm{FU}$ was slightly, but significantly suppressed in both CI99-treated cells and HDAC1 knockdown cells (Figure 3C and D). These results suggest that HDAC1 knockdown reduces 5FU-mediated cell death in HCT116 cells. 

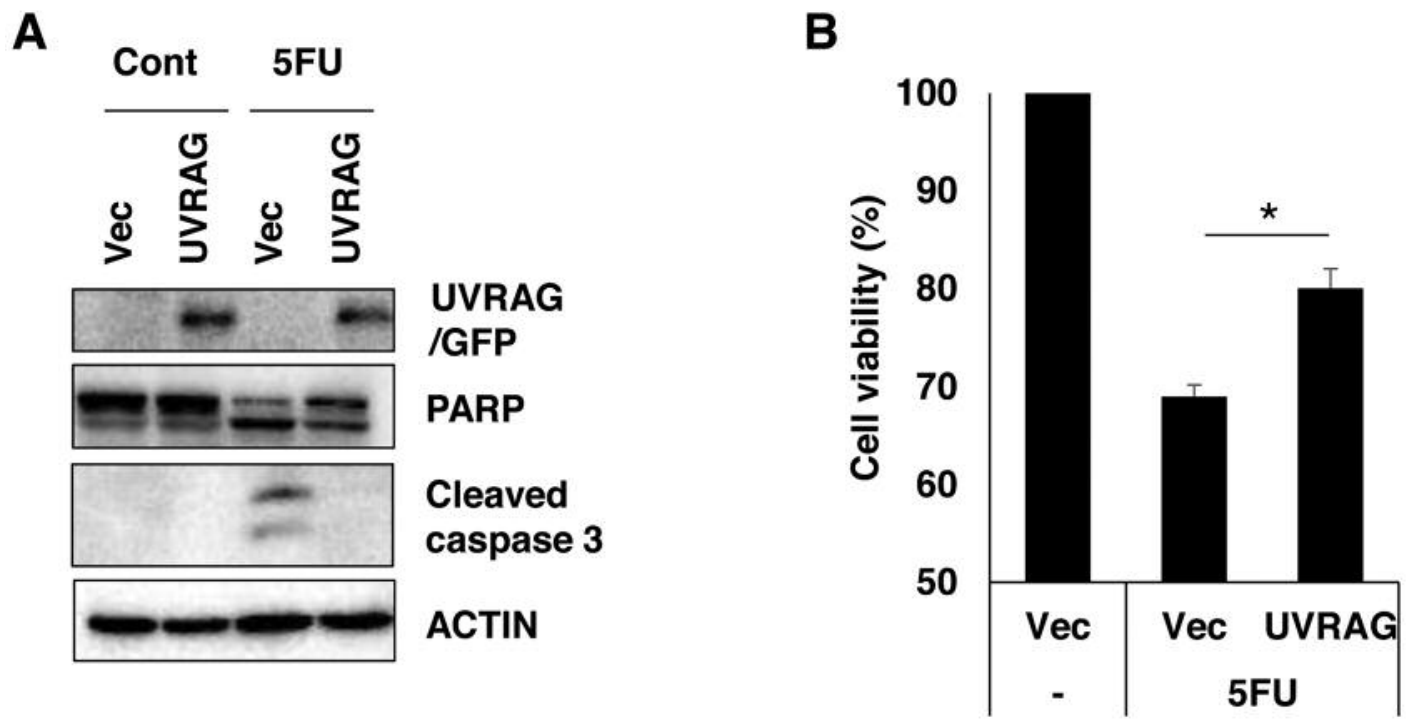

Figure 4. Overexpression of ultraviolent irradiation resistance-associated gene (UVRAG) suppresses 5-fluorouracil (5FU)-mediated cytotoxicity in HCT116 cells. A: HCT116 cells were transfected with a green fluorescent protein (GFP) control plasmid (Vec) or GFP-fused UVRAG plasmid (UVRAG). After $24 \mathrm{~h}$, the cells were treated with $20 \mathrm{mg} / \mathrm{ml} 5 F U$ for $24 \mathrm{~h}$ and expression of poly (ADP-ribose) polymerase (PARP) and cleaved caspase-3 was determined by western blotting. B: HCT116 cells were transfected with GFP control plasmid (Vec) or GFP-fused UVRAG plasmid (UVRAG) and treated with 10,20 , or $50 \mathrm{mg} / \mathrm{ml} 5 F U$ for $24 \mathrm{~h}$, and cell viability of these cells was then determined using a MTT assay. Data are presented as the mean \pm SEM from three independent experiments $(n>3)$. *Significantly different at $p<0.05$.

UVRAG suppresses 5FU-induced cell death in HCT116 cells. We addressed the effect of UVRAG overexpression on 5FUinduced cell death. HCT116 cells transiently transfected with $U V R A G$ plasmid were treated with $5 \mathrm{FU}$, and cell death was determined. As shown in Figure 4, ectopic expression of UVRAG suppressed cell death, as well as caspase activation in 5FU-treated cells. Thus, these results suggest that HDAC1-mediated up-regulation of UVRAG expression inhibits 5FU-induced cell death in HCT116 cells.

\section{Discussion}

Epigenetics affects various cellular and physiological traits, and a number of studies have shown that epigenetic changes also regulate autophagy $(3,4,13,14)$. Recently, our group also reported that ATG6 is transcriptionally repressed by euchromatic histone-lysine $N$-methyltransferase 2 in cancer cells (6). Nonetheless, epigenetic regulation of the expression of various autophagy regulatory proteins has not been elucidated clearly. In this study, we revealed that UVRAG expression is also epigenetically regulated by HDAC1. It was previously reported that UVRAG expression is controlled at both transcriptional and post-transcriptional levels (15-18). Some microRNAs, such as Mir125a and Mir351, directly target and reduce $U V R A G$ expression, which lead to the inhibition of autophagy (15). In addition, Mirl83 targets
$U V R A G$ resulting in negative regulation of $U V R A G$ expression in colorectal cancer (16). Furthermore, protein kinase B (PKB/AKT1)1 inhibits autophagy by reducing UVRAG expression in breast cancer, whereas hepatitis $\mathrm{C}$ virus increases autophagy and UVRAG expression by its replication $(17,18)$. Here, we further revealed that $U V R A G$ is epigenetically regulated. Inhibition of HDAC by chemical inhibitors or genetic knockdown resulted in up-regulation of UVRAG in colorectal cancer cells (Figures 1 and 2).

UVRAG has been implicated in the formation and maturation of autophagosomes and suppression tumorigenicity $(19,20)$. In addition, UVRAG activates the DNA double-strand-break repair system through the increase of DNA protein kinase (21). Consequently, dysregulation of UVRAG increases genetic instability and sensitivity in irradiated cells (21). Deficiency of DNA mismatch repair occurs in over $15 \%$ of sporadic colorectal cancer and $90 \%$ of hereditary nonpolyposis colorectal cancer cases, resulting in microsatellite instability (MSI) (22), and truncated mutations of UVRAG with MSI were reported in colorectal cancer (23). Interestingly, loss of function by truncated mutations of UVRAG increases chemosensitivity to common anticancer agents, such as 5FU, oxaliplatin, and irinotecan in colorectal cancer (9). In accordance with the reports, we also found that forced expression of UVRAG expression suppressed 5FUmediated cell death in colorectal cancer cells (Figure 4). 
Among the class I HDACs, HDAC1, HDAC2, HDAC3 are found in the nucleus, while HDAC8 is localized in both nucleus and cytoplasm (24), and class I HDACs show diverse effects in tumors. In particular, HDAC1 is enhanced in breast, gastric, hepatocellular, lung, pancreatic, and prostate cancer $(25,26)$. Moreover, increased HDAC1 is associated with invasion, differentiation and poor prognosis in various cancer types $(25,26)$. In contrast, inhibition of HDAC1 accelerates leukemogenesis in the early stages, and depletion of HDAC1 leads to increase survival in established tumor cells (26). In this study, we also found that inhibition of HDAC1 suppressed 5FU-mediated cell death in colorectal cancer cells (Figure 3). However, UVRAG is frequently found to be mutated in common types of cancer $(9,27)$. For example, He et al. recently showed that UVRAG is expressed as a truncated mutation (frame shift mutation) which abrogates the normal functions of UVRAG such as autophagy in colorectal cancer (9). The frame shift mutation of UVRAG found in colorectal cancer renders SW480 cancer cells more sensitive to 5FU-mediated chemotherapy(9). Given that individual tumors display extensive intra tumoral heterogeneity, and HDACs epigenetically regulate multiple targets, the effects of inhibition of HDACs on cancer are very complicated and controversial in different cancer cells (28). Nonetheless, HDAC inhibitors represent a promising class of new anticancer agents (29). The disruption of multiple pathways by HDAC inhibitors could contribute to the cytotoxicity found in many of the clinical trials (29). Thus, further investigations are necessary to understand the molecular mechanism of HDAC on UVRAG expression.

In conclusion, the results from our study suggest that UVRAG expression is epigenetically regulated by HDAC 1 , and increased UVRAG expression suppresses 5FU-mediated cell death in colorectal cancer cells.

\section{Acknowledgements}

This study was supported by grants from the National Research Foundation NRF-2017R1A2B4005501 and 2016R1E1A1A029 19844), Ministry of Science, ICT and Future Planning, Republic of Korea

\section{References}

1 Klionsky DJ, Abdelmohsen K, Abe A, Abedin MJ, Abeliovich $\mathrm{H}$, Acevedo Arozena A, Adachi H, Adams CM, Adams PD, Adeli K, Adhihetty PJ, Adler SG, Agam G, Agarwal R, Aghi MK and others: Guidelines for the use and interpretation of assays for monitoring autophagy (3rd edition). Autophagy 12: 1222, 2016.

2 Kaur J and Debnath J: Autophagy at the crossroads of catabolism and anabolism. Nat Rev Mol Cell 16: 461-72, 2015.

3 Lee JM, Wagner M, Xiao R, Kim KH, Feng D, Lazar MA and Moore DD: Nutrient-sensing nuclear receptors coordinate autophagy. Nature 516: 112-115, 2014.
4 Seok S, Fu T, Choi SE, Li Y, Zhu R, Kumar S, Sun X, Yoon G, Kang Y, Zhong W, Ma J, Kemper B and Kemper JK: Transcriptional regulation of autophagy by an FXR-CREB axis. Nature 516: 108-111, 2014

5 Shin HJ, Kim H, Oh S, Lee JG, Kee M, Ko HJ, Kweon MN, Won KJ and Baek SH: AMPK-SKP2-CARM1 signaling cascade in transcriptional regulation of autophagy. Nature 534: 553-557, 2016.

6 Shin HJ, Kim H, Oh S, Lee JG, Kee M, Ko HJ, Kweon MN, Won KJ and Baek SH: Inhibition of EHMT2/G9a epigenetically increases the transcription of Beclin-1 via an increase in ROS and activation of NF-kB. Oncotarget 7: 39796-39808, 2016.

7 Liang C, Feng P, Ku B, Dotan I, Canaani D, Oh BH and Jung JU: Autophagic and tumour suppressor activity of a novel Beclin1binding protein UVRAG. Nat Cell Biol 8: 688-699, 2006.

8 Yin X, Cao L, Kang R, Yang M, Wang Z, Peng Y, Tan Y, Liu L, Xie M, Zhao Y, Livesey KM and Tang D: UV irradiation resistance-associated gene suppresses apoptosis by interfering with BAX activation. EMBO Rep 12: 727-734, 2011.

9 He S, Zhao Z, Yang Y, O'Connell D, Zhang X, Oh S, Ma B, Lee JH, Zhang T, Varghese B, Yip J, Dolatshahi Pirooz S, Li M, Zhang Y, Li GM, Ellen Martin S, Machida K and Liang C: Truncating mutation in the autophagy gene $U V R A G$ confers oncogenic properties and chemosensitivity in colorectal cancers. Nat Commun 6: 7839, 2015.

10 Yang Y, He S, Wang Q, Li F, Kwak MJ, Chen S, O'Connell D, Zhang T, Pirooz SD, Jeon Y, Chimge NO, Frenkel B, Choi Y, Aldrovandi GM, Oh BH, Yuan Z and Liang C: Autophagic UVRAG promotes UV-induced photolesion repair by activation of the CRL4(DDB2) E3 ligase. Mol Cell 62: 507-519, 2016.

11 Choi AM, Ryter SW and Levine B: Autophagy in human health and disease. N Engl J Med 368: 1845-1846, 2013.

12 Falkenberg KJ and Johnstone RW: Histone deacetylases and their inhibitors in cancer, neurological diseases and immune disorders. Nat Rev Drug Discov 13: 673-691, 2014.

13 Xie Y, Zhou B, Lin MY and Sheng ZH: Progressive endolysosomal deficits impair autophagic clearance beginning at early asymptomatic stages in fALS mice. Autophagy 11: 1934-1936, 2015.

14 Fullgrabe J, Ghislat G, Cho DH and Rubinsztein DC: Transcriptional regulation of mammalian autophagy at a glance. J Cell Sci 129: 3059-3066, 2016.

15 Kim Y, Kang YS, Lee NY, Kim KY, Hwang YJ, Kim HW, Rhyu IJ, Her S, Jung MK, Kim S, Lee CJ, Ko S, Kowall NW, Lee SB, Lee $\mathrm{J}$ and Ryu H: Uvrag targeting by Mir125a and Mir351 modulates autophagy associated with Ewsr1 deficiency. Autophagy 11: 796-811, 2015.

16 Huangfu L, Liang H, Wang G, Su X, Li L, Du Z, Hu M, Dong Y, Bai X, Liu T, Yang B and Shan H: miR-183 regulates autophagy and apoptosis in colorectal cancer through targeting of UVRAG. Oncotarget 7: 4735-4745, 2016.

17 Yang W, Ju JH, Lee KM, Nam K, Oh S and Shin I: Protein kinase B/AKT1 inhibits autophagy by down-regulating UVRAG expression. Exp Cell Res 319: 122-133, 2013.

18 Wilson AJ, Byun DS, Popova N, Murray LB, L'Italien K, Sowa Y, Arango D, Velcich A, Augenlicht LH and Mariadason JM: Histone deacetylase 3 (HDAC3) and other class I HDACs regulate colon cell maturation and p21 expression and are deregulated in human colon cancer. J Biol Chem 281: 1354813558, 2006. 
19 Liang C, Feng P, Ku B, Oh BH and Jung JU: UVRAG: a new player in autophagy and tumor cell growth. Autophagy 3: 69-71, 2007.

20 Zhao Z, Ni D, Ghozalli I, Pirooz SD, Ma B and Liang C: UVRAG: at the crossroad of autophagy and genomic stability. Autophagy 8: 1392-1393, 2012.

21 Zhao Z, Oh S, Li D, Ni D, Pirooz SD, Lee JH, Yang S, Lee JY, Ghozalli I, Costanzo V, Stark JM and Liang C: A dual role for UVRAG in maintaining chromosomal stability independent of autophagy. Dev Cell 22: 1001-1016, 2012.

22 Boland CR and Goel A: Microsatellite instability in colorectal cancer. Gastroenterology 138: 2073-2087, 2010.

23 Kim MS, Jeong EG, Ahn CH, Kim SS, Lee SH and Yoo NJ: Frameshift mutation of $U V R A G$, an autophagy-related gene, in gastric carcinomas with microsatellite instability. Hum Pathol 39: 1059-1063, 2008.

24 de Ruijter AJ, van Gennip AH, Caron HN, Kemp S and van Kuilenburg AB: Histone deacetylases (HDACs): characterization of the classical HDAC family. Biochem J 370: 737-749, 2003.

25 Witt $\mathrm{O}$ and Lindemann R: HDAC inhibitors: magic bullets, dirty drugs or just another targeted therapy. Cancer Lett 280: 123-124, 2009 .
26 Santoro F, Botrugno OA, Dal Zuffo R, Pallavicini I, Matthews GM, Cluse L, Barozzi I, Senese S, Fornasari L, Moretti S, Altucci L, Pelicci PG, Chiocca S, Johnstone RW and Minucci S: A dual role for Hdac1: oncosuppressor in tumorigenesis, oncogene in tumor maintenance. Blood 121: 3459-3468, 2013.

27 Knaevelsrud H, Ahlquist T, Merok MA, Nesbakken A, Stenmark $\mathrm{H}$, Lothe RA and Simonsen A: UVRAG mutations associated with microsatellite unstable colon cancer do not affect autophagy. Autophagy 6: 863-870, 2010.

$28 \mathrm{Li} \mathrm{Z}$ and Zhu WG: Targeting histone deacetylases for cancer therapy: from molecular mechanisms to clinical implications. Int J Biol Sci 10: 757-770, 2014.

29 Mottamal M, Zheng S, Huang TL and Wang G: Histone deacetylase inhibitors in clinical studies as templates for new anticancer agents. Molecules 20: 3898-3941, 2015.

Received October 3, 2017

Revised October 26, 2017

Accepted October 31, 2017 